\title{
E-Learning: Educational Video Search through Dynamic Video Annotation
}

\author{
N.Sivaranjani, Amudha S, Mary Linda I
}

\begin{abstract}
Multimedia tools available on the web, particularl y for learning environments, play an important role in the fiel $d$ of education. With the growing number of these multimedia tools, it is important to explore, share, recycle and connect the $m$ to enhance learning experiences. Many videos available on the web lack semantic connections between them even though they have some similarity through their content. Hence to bridge the gap between the semantically related videos, in the proposed system, we adopt the Linked Data technology, in order to semantically annotate the video resources. The relationships between those annotations are stored in the video annotation ontology. The proposed method provides the benefits of high accuracy, performance and good knowledge for the users.
\end{abstract}

Keywords: E-learning, Information Retrieval, Video Annotation Ontology, Linked Data, Semantic Web

\section{INTRODUCTION}

Training is constantly improved by new advancements, particularly with the development of PC related data innovation [2]. E-learning has as of late turned into a promising option in contrast to the conventional study hall realizing which enables the general public to advance toward a dream of deep rooted and on-request learning [3]. It has turned out to be one of the quickest moving patterns [4] and expects to give a configurable foundation that coordinates learning materials, apparatuses, and administrations into a solitary arrangement which can make and convey preparing or instructive substance rapidly, successfully, and financially [5].

Tim Berners-Lee made the vision of Semantic Web dependent on the machine-processable semantics of information that empowers mechanized data access and use [7]. Misusing the semantic connections between ideas is getting a lot of consideration from mainstream researchers on the grounds that doing so can improve the location exactness of ideas and acquire a more extravagant semantic explanation of a video. To this end, ontologies are required to improve the capacity of PC frameworks to consequently

Revised Manuscript Received on December 11, 2019

N.Sivaranjani, Department of Computer science and Engineering, Bharath Institute of Higher Education and Research, Chennai, Tamilnadu, India. Email: ranjibalas@gmail.com

Amudha S, Department of Computer science and Engineering, Bharath Institute of Higher Education and Research, Chennai, Tamilnadu, India.. Email: amudha17s@gmail.com

Mary Linda I, Department of Computer science and Engineering, Bharath Institute of Higher Education and Research, Chennai, Tamilnadu, India. Email: catchlin.18@gmail.com distinguish even complex ideas and occasions from visual information with higher unwavering quality [8].

Ontologies are the backbone technology for the Semantic Web. Ontology is a formal, explicit specification of a shared conceptualisation [9]. A 'conceptualisation' refers to an abstract model of some phenomenon in the world which identifies the concepts that are relevant for that phenomenon.. There are several reasons that people provide to claim the benefits of developing ontology:

- To be able to reuse knowledge.

- To separate the domain knowledge from operational knowledge.

- To analyze domain knowledge.

\section{a. Contributions}

This paper embraces Semantic Web innovation, all the more explicitly, the Linked Data way to deal with location the above difficulties. The significant commitments of our methodology are recorded underneath.

1. Video annotation ontology is designed for annotating on the timeline streams. This allows more accurate description details to be added to the video.

2. A semantic video explanation device is actualized for commenting on and distributing instructive video assets dependent on the video comment cosmology. It enables dynamic comments to be added to the video utilizing the Linked information to portray the video assets. These explanations connect to the next video assets accessible.

The rest of the paper covers background and related work discussions (Section 2), the overall platform architecture (Section 3), the detailed illustration on the video retrieval process (Section 4), experimental evaluation process(Section $5)$.

\section{BACKGROUND AND RELATED WORK}

Getting to interactive media content in correspondence with the significance related to a client, comprises the center test in sight and sound research, generally alluded to as the semantic hole [10]. Because of unstructured and straight highlights of recordings, the fundamental instructional substance of most e-learning frameworks, the introduction recordings, has not been completely misused. These disadvantages limit the productivity, convenience and reusability of the instructive video assets.

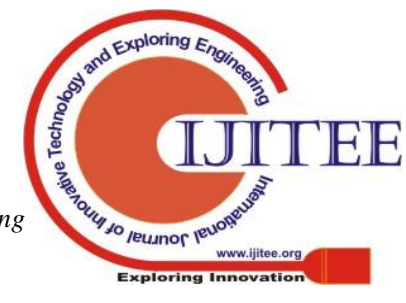




\section{E-Learning: Educational Video Search through Dynamic Video Annotation}

To guarantee compelling abuse of these video resources, proficient and adaptable access instruments must be given.

Video comment information assume a basic job in video frameworks. The powerful use of the video information is acquired through the more extravagant explanation information and the more adaptable video get to [11]. Additionally, it would empower understudies to increase an increasingly exhaustive comprehension of the point from alternate points of view if those comments are linkable to other applicable taking in information from both inner and outside assets.

\section{A. Linked Data}

Connected Data is basically about utilizing the Web to make composed connections between information from various sources. They might be as various as databases which are kept up by associations present in a wide range of land areas, or divergent frameworks inside one association that have not effectively interoperated at the information level verifiably. In specialized terms, Linked Data alludes to information distributed on the Web so that it is machine-comprehensible with their implications expressly characterized, so it very well may be connected to other outer informational indexes, and are linkable further to other information on the web [12].

1. Data are distinguished by URIs,

2. The URIs can be dereferenced,

3. The dereferenced information contain increasingly valuable data about the information, and

4. More information are effectively discoverable on the web scale.

- Favorable circumstances of utilizing Linked Data to make video comments for the instructive space:

- Each video comment is one of a kind and expressly recognized.

- Information is connected to the enormous information net.

- Videos can be connected to one another.

- Gathers helpful learning from the web.

\section{B. Seamless annotation \& enrichment of mobile captured video streams:}

This explanation method is proposed for portable caught video streams. This framework gives clients ongoing naturally created labels of their right now caught recordings [13]. It is a totally unaided explanation strategy. It doesn't compel labeling jargon as done in managed learning models [14].

\section{Semi-automatic video content annotation:}

In this paper [15] to clarify video content viably and precisely, video content depiction metaphysics is proposed, and after that a self-loader comment procedure is presented which uses different video handling methods to enable the annotator to investigate video setting or situations for explanation.

\section{Ontology based automatic video annotati- -on technique:}

In this paper [16], a programmed video comment strategy is exhibited for brilliant TV condition which utilizes the ontologies to present the video recovery and sharing procedure in keen TV condition.

Next we survey some typical video annotation tools available with their features.

\section{E. Vannotea:}

Empower clients accessible on access framework hubs to cooperatively join enlightening, rights and inborn consideration metadata and explanations to advanced pictures, video or 3D portrayals. Sharing and trade of information will ideally revive societies disintegrated through colonization and globalization. Comments were not in a semantic web style [17].

\section{F. M-OntoMat-Annotizer:}

It allows linking low level MPEG-7 visual descriptions to conventional semantic web ontologies and annotations that contain high level domain concepts

\section{G. Video and Image Annotation:}

By means of backings clear, auxiliary and media metadata of picture and video resources dependent on a client stacked OWL cosmology where free content portrayals can likewise be included. The comments can be performed for whole video, video sections, moving locales, outlines or even still pictures inside a casing progressively on MPEG-1 and MPEG-2 recordings [20].

\section{ARCHITECTURE OF THE SYSTEM}

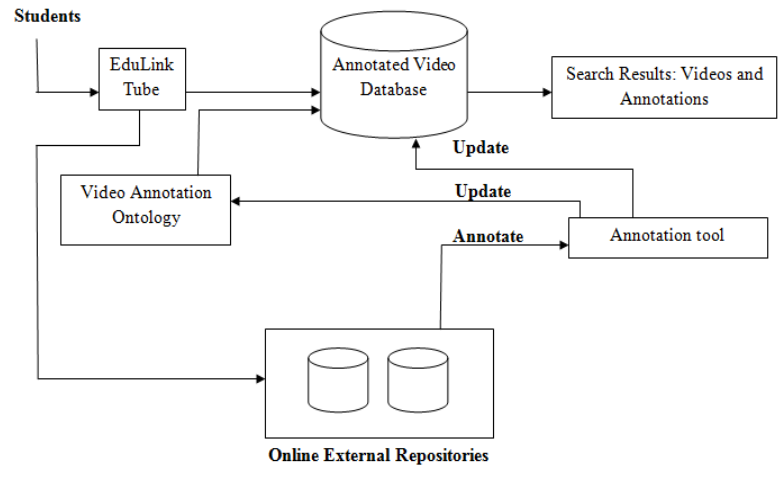

Figure 1: System Architecture For Dynamic Video Retrieval Process

EduLinkTube is a video search tool designed mainly for the students for their academic purposes. The student who wants to study online gives the keyword for search. The search is initially directed to the local online database to check if any related videos are available. 
If they are available, those videos and their annotations (i.e) links are retrieved and displayed. The video annotation ontology is responsible for providing the annotations. When the videos are not present in the local database, the search is directed to the web resources. The accurate video for the terminology is extracted and given as input to the annotation tool. Annotation for the videos will be done based on the timeline of the video. Once the annotation process is complete, the video annotation ontology gets updated will the annotations and their relationships. Also our local database is uploaded with that particular video and its related videos which are then retrieved by the EduLinkTube and displayed to the student.

\section{PROCESS FLOW FOR DYNAMIC VIDEO RETRIEVAL}

Our approach is based on the Linked Data technology to relate the various video resources. The steps involved in the video retrieval process are as follows:

\section{A. Designing EduLinkTube}

The user requires an interface for him/her to communicate with the system. So we design an online tool, EduLinkTube for the users to semantically search his interesting topics. This tool is enhanced with several other functionalities to gain knowledge on the topic. Basically, Windows Media Player is used for viewing the videos. Interesting information from the web regarding the search topic can be retrieved and viewed. Most importantly, the tool also performs the annotation process automatically as per the video input using Information Extraction (IE) method. Annotations may be performed based on the timeline of the video.

\section{B. Keyword Search}

Our tool performs two types of Information Retrieval (IR) process: Keyword Search and Semantic Search. Keyword search is based on the indexing technique to retrieve the video. Indexing is done in both the internal and external repositories each time the student gives the query. All videos related to the keyword will also be displayed.

\section{Video Annotation (Preliminary Stage}

Ontology

Creation

In this stage, we start with making a basic philosophy for the current recordings in the database. From the syntactic perspective, we accept that the components of enthusiasm for the client are built on the grounds of some crude terms. As indicated by this presumption, philosophy comprises of crude classes and compound classes. The crude classes are the least difficult ideas that can't be amassed from different classes. Notwithstanding, they might be additionally acquired by inferred ideas or their youngsters (e.g., sub terms). Along these lines, in this progression, the principle undertaking is to make the straightforward and the compound ideas.

Different terms which express the same concepts are identified. Using the protégé ontology editor, we start building the ontology for the subjects in the database. The super class will be the name of the subject and the sub classes will be the concepts related to it. We use some properties like comment, sameAs, seeAlso, subClassOf to form the video hierarchy. This step called the annotation inferencing process, serves as the base for the semantic search process.

\section{Dynamic Video Annotation}

In this section we attempt to dynamically annotate the video resources obtained from the external repositories. Annotation is the process of adding metadata to the video. Semantic search is performed statically using the ontology we created for the videos in the database. But when we try to search videos from the external sources, those videos should be added to our database automatically along with their annotations.

Annotation for the dynamic process will be based on the timeline of the video adopting the Linked Data principles. A terminology and link will be extracted for a particular time of the video. Similarly many keywords and links will be generated for the entire video and is stored in the database. These links serves as the annotations for the different resources from the web.

\section{E. Ontology Update}

The ontology update annotations for the dynamically added videos are stored in the database for each new keyword searched, the ontology for the corresponding annotations should also be updated.

Again the annotation inferencing process is carried out with many properties mentioned earlier. Since both keywords and links are generated as annotations for the dynamic search process it is important that relationship between them should be bridged accordingly in the ontology also. The timeline information may also be stored in the ontology so that particular frames of the video for a keyword can be exactly extracted /retrieved from the entire video. This process is very complex and time consuming since everything is happening automatically and dynamically.

\section{F. Linked Data Based Video Retrieval}

Recordings accessible at our database are commented on with time sensitive metadata which requests advanced hunt strategies, to give the client a useful asset to explore the information. Best in class catchphrase based inquiry advancements are utilized to give a quick and productive access, however by and by the watchword based pursuit experience is somewhat uni-dimensional. So we send Semantic Web advances to enhance query items of our inquiry device and improve client's understanding by empowering a semantically bolstered explorative pursuit.

In this step, we make use of the ontology and their corresponding annotations to provide accurate semantic search results to the students. 
When a keyword is given for search, all its annotations are retrieved. The annotations when dereferenced play the video and related content of that video will also be displayed in our tool.

\section{RESULTS}

Finding the necessary data rapidly and effectively on the web stays a significant test. Data recovery is the action of acquiring data assets pertinent to a data need from a gathering of data assets. Most IR frameworks process article in the database coordinates the question, and rank the items as indicated by this worth. The articles positioned at the top are then appeared to the client.

Thinking about our proposed framework, we utilize two clear assessment estimates got from the data recovery network, in particular, exactness and review.

In data recovery settings, exactness is the part of recovered archives that are significant to the inquiry:

$$
\text { precision }=\frac{\mid\{\text { relevant documents }\} \cap\{\text { retrieved documents }\} \mid}{\mid\{\text { retrieved documents }\} \mid}
$$

$$
\text { recall }=\frac{\mid\{\text { relevant documents }\} \cap\{\text { retrieved documents }\} \mid}{\mid\{\text { relevant documents }\} \mid}
$$

Accuracy and review are characterized regarding a lot of recovered records (for example the rundown of reports delivered by a web search tool for a question) and a lot of applicable records (for example the rundown of all archives on the web that are significant for a specific point).

\section{CONCLUSION}

This paper represented the EduLinkTube stage that utilizations Linked Data innovations to semantically explain and look through instructive video assets from the online video store and connection the recordings to other instructive assets on the web. In the semantic comment process, 1) a video explanation metaphysics is characterized to help comments dependent on Linked Data; 2) Linked Data Services are coordinated to completely bolster dynamic comment URI recommendations into the comment interface. Removing learning from accessible video is one further challenge to Ontology Engineering. In the semantic pursuit process, the inquiry strategies depend on the information recovered through Linked Data Services and URIs, which are basic to connection related information from various assets together to improve the first video query items. Our proposed technique demonstrates that e-learning assets conveyed crosswise over various instructive associations can be connected together to give more esteem included data.

\section{REFERENCES}

1. Kumaravel A., Meetei O.N.,An application of non-uniform cellular automata for efficient cryptography,2013 IEEE Conference on Information and Communication Technologies, ICT 2013,V-,I-,PP-1200-1205,Y-2013

2. Kumarave A., Rangarajan K.,Routing alogrithm over semi-regular tessellations,2013 IEEE Conference on Information and Communication Technologies, ICT 2013,V-,I-,PP-1180-1184,Y-2013

3. Dutta P., Kumaravel A.,A novel approach to trust based identification of leaders in social networks,Indian Journal of Science and Technology,V-9,I-10,PP--,Y-2016

4. Kumaravel A., Dutta P.,Application of Pca for context selection for collaborative filtering,Middle - East Journal of Scientific Research,V-20,I-1,PP-88-93,Y-2014

5. Kumaravel A., Rangarajan K.,Constructing an automaton for exploring dynamic labyrinths,2012 International Conference on Radar, Communication and Computing, ICRCC 2012,V-,I-,PP-161-165,Y-2012

6. Kumaravel A.,Comparison of two multi-classification approaches for detecting network attacks, World Applied Sciences Journal,V-27,I-11,PP-1461-1465,Y-2013

7. Tariq J., Kumaravel A.,Construction of cellular automata over hexagonal and triangular tessellations for path planning of multi-robots,2016 IEEE International Conference on Computational Intelligence and Computing Research, ICCIC 2016,V-,I-,PP--,Y-2017

8. Sudha M., Kumaravel A.,Analysis and measurement of wave guides using poisson method,Indonesian Journal of Electrical Engineering and Computer Science,V-8,I-2,PP-546-548,Y-2017

9. Ayyappan G., Nalini C., Kumaravel A., Various approaches of knowledge transfer in academic social network,International Journal of Engineering and Technology,V-,I-,PP-2791-2794,Y-2017

10. Kaliyamurthie, K.P., Sivaraman, K., Ramesh, S. Imposing patient data privacy in wireless medical sensor networks through homomorphic cryptosystems 2016, Journal of Chemical and Pharmaceutical Sciences

11. Kaliyamurthie, K.P., Balasubramanian, P.C. An approach to multi secure to historical malformed documents using integer ripple transfiguration 2016 Journal of Chemical and Pharmaceutical Sciences 9

12. A.Sangeetha,C.Nalini,'Semantic Ranking based on keywords extractions in the web", International Journal of Engineering \& Technology, 7 (2.6) (2018) 290-292

13. S.V.GayathiriDevi,C.Nalini,N.Kumar,"An efficient software verification using multi-layered software verification tool "International Journal of Engineering \& Technology, 7(2.21)2018 454-457

14. C.Nalini,ShwtambariKharabe,"A Comparative Study On Different Techniques Used For Finger - Vein Authentication", International Journal Of Pure And Applied Mathematics, Volume 116 No. 8 2017, 327-333, Issn: 1314-3395

15. M.S. Vivekanandan and Dr. C. Rajabhushanam, "Enabling Privacy Protection and Content Assurance in Geo-Social Networks", International Journal of Innovative Research in Management, Engineering and Technology, Vol 3, Issue 4, pp. 49-55, April 2018.

16. Dr. C. Rajabhushanam, V. Karthik, and G. Vivek, "Elasticity in Cloud Computing", International Journal of Innovative Research in Management, Engineering and Technology, Vol 3, Issue 4, pp. 104-111, April 2018.

17. K. Rangaswamy and Dr. C. Rajabhushanamc, "CCN-Based Congestion Control Mechanism In Dynamic Networks", International Journal of Innovative Research in Management, Engineering and Technology, Vol 3, Issue 4, pp. 117-119, April 2018.

18. Kavitha, R., Nedunchelian, R., "Domain-specific Search engine optimization using healthcare ontology and a neural network backpropagation approach", 2017, Research Journal of Biotechnology, Special Issue 2:157-166

19. Kavitha, G., Kavitha, R., "An analysis to improve throughput of high-power hubs in mobile ad hoc network", 2016, Journal of Chemical and Pharmaceutical Sciences, Vol-9, Issue-2: 361-363

20. Kavitha, G., Kavitha, R., "Dipping interference to supplement throughput in MANET", 2016, Journal of Chemical and Pharmaceutical Sciences, Vol-9, Issue-2: 357-360 
21. Michael, G., Chandrasekar, A.,"Leader election based malicious detection and response system in MANET using mechanism design approach", Journal of Chemical and Pharmaceutical Sciences(JCPS) Volume 9 Issue 2, April - June 2016.

22. Michael, G., Chandrasekar, A.,"Modeling of detection of camouflaging worm using epidemic dynamic model and power spectral density", Journal of Chemical and Pharmaceutical Sciences(JCPS) Volume 9 Issue 2, April - June 2016.

23. Pothumani, S., Sriram, M., Sridhar, J., Arul Selvan, G., Secure mobile agents communication on intranet,Journal of Chemical and Pharmaceutical Sciences, volume 9, Issue 3, Pg No S32-S35, 2016

24. Pothumani, S., Sriram, M., Sridhar, Various schemes for database encryption-a survey, Journal of Chemical and Pharmaceutical Sciences, volume 9, Issue 3, Pg NoS103-S106, 2016

25. Pothumani, S., Sriram, M., Sridhar, A novel economic framework for cloud and grid computing, Journal of Chemical and Pharmaceutical Sciences, volume 9, Issue 3, Pg No S29-S31, 2016

26. Priya, N., Sridhar, J., Sriram, M. "Ecommerce Transaction Security Challenges and Prevention Methods- New Approach” 2016 ,Journal of Chemical and Pharmaceutical Sciences, JCPS Volume 9 Issue 3.page no:S66-S68

27. Priya, N.,Sridhar,J.,Sriram, M."Vehicular cloud computing security issues and solutions" Journal of Chemical and Pharmaceutical Sciences(JCPS) Volume 9 Issue 2, April - June 2016

28. Priya, N., Sridhar, J., Sriram, M. "Mobile large data storage security in cloud computing environment-a new approach” JCPS Volume 9 Issue 2. April - June 2016

29. Anuradha.C, Khanna.V, "Improving network performance and security in WSN using decentralized hypothesis testing "Journal of Chemical and Pharmaceutical Sciences(JCPS) Volume 9 Issue 2, April - June 2016.

\section{AUTHORS PROFILE}

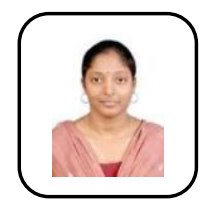

N.Sivaranjani Assistant Professor, Department of Computer science and Engineering, Bharath Institute of Higher Education and Research, Chennai, India

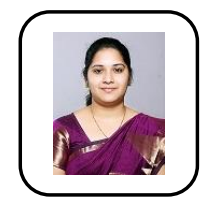

Amudha S Assistant Professor, Department of Computer science and Engineering, Bharath Institute of Higher Education and Research, Chennai, India

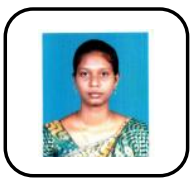

Mary Linda I Assistant Professor, Department of Computer science and Engineering, Bharath Institute of Higher Education and Research, Chennai, India 